\title{
Research on the Status and Causes of the Problems of Mobile Network Games in Junior High School Students
}

\author{
Weizhen Zhang ${ }^{1, *}$ \\ ${ }^{1}$ School of Political Science and Law, University of Jinan \\ EEmail:1677355473@163.com

\begin{abstract}
Based on the relevant research on online games, this paper takes junior high school students as the research object, analyzes the status of junior high school students' mobile online games from four aspects: the time of playing mobile games, the types of mobile games they prefer, the reasons and feelings of playing mobile games, and the cognition of the influence of mobile games on themselves. At the same time, through semi-structured interviews, we can deeply understand the influencing factors junior high school students' questions on mobile online games systematically. According to its, this paper hopes to provide reference for future research.
\end{abstract}

Keywords: junior high school students, mobile games, cause analysis, case study

\section{INTRODUCTION}

\subsection{Research Background}

According to a report by the China Internet Network Information Center (CNNIC), mobile online game users in China reached 516 million as of December 2020, accounting for 52.4 percent of the country's mobile Internet users. It can be seen that more than half of the mobile Internet users will play mobile games. In the age structure of Chinese netizens, the age group of 10-19 years old accounts for $13.5 \%$ of the whole netizens. In the educational background structure, the junior middle school education accounted for $40.3 \%$; In the occupational structure, students are the largest group, accounting for $21.0 \%{ }^{[1]}$. It can be seen that junior high school students are not only an important part of mobile Internet users, but also occupy a considerable position among mobile game users.

Compared with other audiences, the risk of teenagers' addiction to online games is much higher than that of other groups ${ }^{[2]}$. On the one hand, online games satisfy the needs of achievement, belonging and communication ${ }^{[3]}{ }^{[4]}$, and also improve the ability of teamwork ${ }^{[5]}$ and stimulate thinking ${ }^{[6]}$. But once indulged in it, it not only harms physical health ${ }^{[7]}$, but also further confuses teenagers' self-cognition, induces personality disorders ${ }^{[8]}$, and eventually leads to criminal behavior ${ }^{[9]}$. In addition, the news caused by students' addictions to mobile phone games has had a huge social impact and aroused further thinking of scholars. Therefore, it is urgent to understand the current situation of junior high school students playing mobile phone games and grasp the systematic factors of junior high school students' addiction to mobile phone games.

\subsection{Research Significance}

Analyzing the current situation of mobile phone games of junior high school students can deeply grasp the psychological and behavioral characteristics of junior high school students on playing mobile phone games, which can make up for the deficiency of the current research mainly focusing on the large group of teenagers and the field of online games, and make the focus more concentrated. At the same time, the ecological system theory as a guide to the corresponding case analysis, not only can fully grasp the beguiled by the reason of the mobile phone games, than in the past focus on a particular genetic research is more system, and expand the relevant theories on the research of the mobile phone games, can provide theoretical reference for subsequent scholars research experience.

\section{RESEARCH METHOD AND PROCESS}

\subsection{Literature research method}

This paper consulted professional books, periodicals and academic papers related to online game addiction. 
Through sorting and summarizing, analyzing and combing, the research framework was constructed, and the actual situation of junior high school students playing mobile games was linked to lay the foundation for the research.

\subsection{Questionnaire survey}

In order to understand the current situation of junior high school mobile phone games, Huantai County a junior high school students as an example to conduct an investigation. After the questionnaire was formulated, it was randomly distributed to all the students of the school, and 106 questionnaires were collected in total. After excluding invalid questionnaires, through the analysis of 94 questionnaires playing mobile game, we have a basic grasp of the situation of junior middle school students playing mobile games, mainly including the time of playing mobile games, the reasons and feelings of playing mobile games, and the cognition of the influence of mobile games on themselves.

\subsection{Semi-structured interview method}

After understanding the basic situation of junior high school students' playing mobile games through previous literature research, the author conducted a case study in March 2019, that is, a semi-structured interview was conducted on the case of mobile game addiction, so as to have an in-depth understanding of the personal, family, school and other factors leading to their addiction to mobile games. From the micro point of view, together with the data obtained from the macro point of view, to ensure the completeness of the research.

\section{INVESTIGATION ON THE STATUS OF MOBILE GAMES AMONG JUNIOR HIGH SCHOOL STUDENTS}

\subsection{Junior high school students play mobile game frequently and time-consuming}

Among all respondents, 88.7 percent of junior high school students said they play mobile games. During school, $63.83 \%$ of the students play mobile games for less than 1 hour every day, and the time spent is reasonable. However, $11.70 \%$ of the students still play games for more than two hours a day. Compared with school, junior middle school students spend significantly more time playing mobile phone games on weekends and holidays, and $50.00 \%$ of them spend more than 2 hours playing games. In addition, 44.68\% of the students have been playing mobile games for more than 1 year; $37.2 \%$ of the students said they could play the same game for more than 6 months. It can be seen that junior high school students spend more time on mobile games.

\subsection{Junior high school students have different cognition of the influence of hand games}

Through the overall analysis of the data, on the one hand, $43.62 \%$ of junior high school students said that they often think of mobile phone games when they are addicted to them, and $41.48 \%$ of junior high school students said that it is difficult to reduce or control the time they spend playing mobile phone games, which affects their study and life. On the other hand, 58.51\% of the students regard mobile games as a means to get rid of worries and rages, and admit the positive influence of it. And $42.56 \%$ of junior high school students said that mobile games would not affect their grades and the relationship with their classmates. It can be concluded that although junior middle school students admit that they are addicted to games, most of them think that mobile phone games have more positive effects than negative ones.

\subsection{Social attributes have a profound impact on junior high school students' playing mobile game}

The survey found that, regardless of grade and gender, although junior high school students play mobile phone games to get rid of troubles, social communication via it is becoming increasingly prominent: when more than half of his classmates are playing games, he will be initiative to contact this game and often discuss the game with his classmates. Firstly, it relates to the nature of mobile games themselves. Depends on rapid development and popularity of mobile Internet technology, mobile phone game, mobile in the presentation and social characteristics of increasingly prominent ${ }^{[10]}$. On the other hand, most of the mobile phone games can log in directly by social software, students can see whether to have friends online, and interactive, so form a strong social mechanism. On the other hand, most mobile games also have public screens. Students can also make friends in the games through it, which further strengthens their social nature. Secondly, it is also related to the group conformity psychology of junior high school students. Games will strengthen group identity and influence people inside and outside the group. Such an invisible social process has a greater impact on immature junior high school students ${ }^{[11]}$.

\section{REASONS FOR JUNIOR HIGH SCHOOL STUDENTS' ADDICTION TO MOBILE GAMES -- A CASE STUDY}

\subsection{Case overview}

Junior high school student Z, female, 15 years old, junior high school third grade. He plays mobile game frequently, almost every day to play, even if not to play, 
he also wants to $\log$ in to receive rewards. According to $\mathrm{Z}$, at first he played the game because he had a mobile phone and downloaded it out of curiosity. However, he was introduced to Personality Five by a friend. On the one hand, he was attracted by the graphics, special effects and unique competition system of the game, and on the other hand, he wanted to play with his classmates and have common topics. In terms of the experience of playing mobile game, he thinks it can relieve the pressure of study and deepen the relationship with classmates; On the other hand, as a result of being addicted to mobile game and watching live games, his grades declined, which also affected relationship with parents. His parents, who were neutral about the game and were busy with their jobs, basically didn't limit it. However, since it has affected study, the teachers have talked to him and parents confiscate phone directly. But it doesn't work. He still finds excuses to play games, but it is hard to control the change.

\subsection{Analysis of the reasons for junior high school students' addiction to mobile games}

Ecosystem theory regards people's living environment as a large social ecosystem, and people and their environment are interdependent and complementary. At the same time, ecosystem theory emphasizes the interaction between individual behavior and various systems of social environment, as well as the significant impact of environment on human behavior, namely the so-called "man in context" [12]. Therefore, mobile game addiction of junior high school students is not only caused by junior high school students themselves, but also affected by family, school, social environment and other external factors.

\subsubsection{Unique psychological characteristics of junior high school students}

From the perspective of ecosystem, junior high school students are in a complex network environment, and their behavior is affected by both internal psychological characteristics and external environment. At the same time, because they are in the special stage of adolescence, their unique psychological characteristics will also become the reason why they are addicted to mobile phone games. First of all, junior high school students have strong curiosity and are easily attracted by new things to try. Faced with various content and rich forms of mobile phone games, they are often willing to accept them. Secondly, driven by conformity and rebelliousness, junior high school students will unconsciously spend more time on mobile phone games, either under the influence of their classmates or against the discipline of their parents. At the same time, due to their poor self-control, once they come into contact with mobile games, they are often difficult to control and easy to indulge.

\subsubsection{Disharmonious family environment factors}

For junior high school students, family is the most important socialization institution. Personal growth, the formation of values and the establishment of behavior patterns are all influenced by family. Similarly, junior high school students who were addicted to mobile game were strongly influenced by their home environment. First of all, with the improvement of family economic level, parents usually equip their children with mobile phones, which provides conditions for junior high school students to play mobile games. Secondly, parents underestimate the influence of their words and deeds on their children and fail to set an example, which have a subtle effect on children's play. Finally, family members lack interpersonal communication. Once the parents found that the child was addicted to mobile game, in the absence of effective talk, only to confiscate mobile phones and other compulsory measures, which is easy to provoke the child's rebellious psychology, but appear more tube more want to play the situation, but also encourage the child to swim addictions.

\subsubsection{Conformity influence of peer groups}

Peer groups in school are the most frequent contacts of junior high school students except parents, and they have a great influence on each other. Whether questionnaire survey or case interview, it is found that the role of peer group in junior high school students' mobile game obsession cannot be ignored. On the one hand, whether peers play mobile phone games and what kind of mobile phone games they play will affect junior high school students' own behaviors and choices. On the other hand, as one of the platforms for junior high school students to exchange information and opinions, peer groups make junior high school students strengthen the influence of games on themselves through constant exchange of views. In addition, peer groups may also form corresponding group identity due to games, and this social process has a great impact on junior high school students: in order to integrate into the group, they need to play games [13].

\subsubsection{Imperfect school teaching system and management system}

For junior high school students, school is the most important place for activities, and school teaching will also have an impact on junior high school students' playing mobile games. First of all, the exam-oriented education still exists, and junior high school students are under great learning pressure. In addition, the arrangement of extracurricular activities is less, the form is single, and the interest is not strong. To a certain extent, junior high school students will release their pressure and have fun through mobile games. Secondly, the content of relevant educational activities is 
monotonous and the form is traditional, which fails to help junior middle school students to view mobile game objectively and impartially, and fails to give full play to the positive role of mobile game. Finally, teachers' fixed education mode, ignoring students' attitudes, ideas and needs in mobile games, will cause them to have rebellious psychology to a certain extent and aggravate their addiction.

\subsubsection{Disadvantageous social supervision}

Junior high school students in the social environment, the emergence of addiction to mobile phone games is also affected by the problem. First of all, government supervision is not in place, and relevant parties of mobile games are not subject to targeted laws and regulations. Secondly, in the context of the broad prospects of the current game market, in order to seek profits, game companies excessively pursue excitement and novelty, and mobile games with uneven quality surge, attracting the attention of many junior high school students. Finally, network media generally publicize the negative effects brought by mobile games, which cannot guide junior middle school students to view mobile games correctly and fail to play the educational role of media.

\section{CONCLUSION}

Based on the questionnaire survey and in-depth interview of junior high school students, this paper has a full-scale understanding of the time and cognition of junior high school students playing mobile games, and analyzes the reasons for mobile game addiction by using the ecosystem theory, which mainly includes the factors of individuals, families, peer groups, schools, society.

Due to the limited ability of the author, there are some defects in the questionnaire design and so on. In addition, the author only took the students of a middle school in Huantai County as an example, which cannot represent all junior high school students, and the universality is low. I hope to conduct more comprehensive and in-depth research in the future.

\section{REFERENCES}

[1] China Internet Network Information Center (CNNIC). Statistical Report on China Internet Development Status [R], 202:2.

[2] Griffiths, M.D., Kiraly, \& Pontes, O. (2015). An overview of self-made gaming. In V. Tarcevic \& E. Boujaoude (EDS.), Mental Health in the Digital Age: Grave Dangers. Great Promise. Oxford: Oxford University Press. 27-45.

[3] Cai Yuanyuan, Cui Lijuan, Li Ting. A Study on the Psychological Needs of Adolescent Online Game
Behavior [J]. Psychological Science, 2007(1):169-172.

[4] Li Jing. Analysis on Psychological Needs of Online Game Consumption Behavior of Urban Middle School Students $\quad[\mathrm{J}]$. Youth Exploration,2009(02):74-77.

[5] Xu Xiaolong, Cheng Chunling, Sun Lijuan. Analysis of the influence of online games on teenagers $[\mathrm{J}]$. Journal of Southeast University (Philosophy and Social Science Edition), 2010 (1).

[6] ZHANG Yan-zhen, ZHANG Wei, WU Qiu-lin, et al. Chinese Journal of Health Psychology,2016,24(4):570-572,573. (in Chinese with English abstract)

[7] $\mathrm{Wu}$ Hao. The hidden problems behind social networking sites -- based on an empirical survey of 120 "Kaixin" users [J]. China Youth Research, 2009 (09) :48-51.

[8] Li Ming. Research on the Physical and Mental Influence of Online Games on Adolescents [D]. Wuhan University of Technology,2008.

[9] Liu J. Analysis of the Relationship between Online Game Addiction and Juvenile Crime [D]. Beijing: China University of Political Science and Law, 2011 (3).

[10] Huang Jianjun, Ding Jixiong. A Brief Analysis of the Social Development of Mobile Games: A Case Study of PUBG: Battlefield [J]. This media, 2019, 27 (3) : 14-17.

[11] Tian Feng, Wu Si, Liu Hongsen, Lu Xinhe. Games and youth growth -- A discussion based on the sample of King of Glory [J]. Journal of Youth,2017(04):86-93.

[12] Chen Jiahui, Li Yongtu. Journal of Hebei Youth Management Cadre Institute,2017,29(03):23-25. (in Chinese)

[13] Tian Feng, Wu Si, Liu Hongsen, Lu Xinhe. Games and youth growth -- A discussion based on the sample of King of Glory [J]. Journal of Youth,2017(04):86-93. 